\title{
Involvement of the S-layer proteins Hpi and SIpA in the maintenance of cell envelope integrity in Deinococcus radiodurans $\mathrm{R} 1$
}

\author{
Heather Rothfuss, ${ }^{1}$ Jimmie C. Lara, ${ }^{2}$ Amy K. Schmid ${ }^{3} \dagger$ \\ and Mary E. Lidstrom ${ }^{1,2}$
}

Correspondence

Mary E. Lidstrom

lidstrom@u.washington.edu

Received 3 March 2006

Revised 31 May 2006

Accepted 14 June 2006

\begin{abstract}
Department of Chemical Engineering ${ }^{1}$, Department of Microbiology ${ }^{2}$ and Program in Molecular and Cellular Biology ${ }^{3}$, University of Washington, Seattle, WA 98195, USA
\end{abstract}

\section{INTRODUCTION}

Crystalline surface layers (S layers) made of proteins or glycoproteins are a commonly observed surface structure in prokaryotes (Sleytr et al., 1993). Most S-layer proteins possess a signal sequence, predominantly contain hydrophobic and acidic amino acids, and, with the exception of archaeal S layers, are low in sulfur-containing amino acids (Kuen \& Lubitz, 1996; Kuen et al., 1996; Sleytr et al., 1993). Several strains possess more than one S-layer protein, and these may be co-expressed or selectively expressed in response to specific environmental conditions (CoutureTosi et al., 2002; Sleytr et al., 1993). The S-layer protein(s) may represent up to $15 \%$ of cell mass when present, causing a burden on the cell (Sleytr et al., 1993) that may lead to Slayer loss after long-term cultivation under idealized laboratory conditions (Sleytr et al., 1993; Thompson et al., 1982).

A number of functions have been proposed for S layers, which in some cases have been experimentally confirmed (Beveridge et al., 1997; Rachel et al., 1997; Sleytr et al., 1993). These include adhesion, enzyme attachment, prevention of adsorption of macromolecules, and cellular stability and rigidity (Beveridge et al., 1997; Rachel et al., 1997; Sleytr

tPresent address: Institute for Systems Biology, $1441 \mathrm{~N}$ 34th St, Seattle, WA 98103, USA.

Abbreviations: HPI, hexagonally packed intermediate; S layer, surface layer; SEM, scanning electron microscopy; SLH, S-layer homology. et al., 1993). The surface layers of Deinococcus radiodurans strains SARK and R1 have been closely studied since the early 1960s, the initial interest being rooted in the extreme radiation resistance of these organisms (Thornley et al., 1965). The role of $S$ layers in this extreme resistance has not yet been demonstrated, but a role in response to radiation damage has been proposed (Gentner \& Mitchel, 1975). A diagram of the cell envelope structure in $D$. radiodurans as proposed by Emde et al. (1980) is shown in Fig. 1. Stacked upon the inner membrane face are a peptidoglycan layer, an interstitial layer, and the 'pink envelope'. The pink envelope contains the S layer [hexagonally packed intermediate (HPI) layer and lipid-rich backing], lipids, carbohydrates, proteins, four to five carotenoids, and most likely the outer membrane (Kübler \& Baumeister, 1978; Thompson et al., 1982; Work \& Griffiths, 1968). The outermost layer of the pink envelope is a long-chain carbohydrate coat, and in $5-10 \%$ of the cell population it is only minimally present (Baumeister et al., 1981; Emde et al., 1980). Of the pink envelope components, the hexagonal network of the outer surface array has received the most attention. The $S$ layer is predominantly made up of one protein, Hpi (Baumeister et al., 1982; Peters \& Baumeister, 1986). It has been proposed that hydrophobic interactions are responsible for attachment of the $S$ layer to the outer membrane in the backing layer, as well as for the association of the S-layer units (Thompson et al., 1982). Although the HPI layer itself has been characterized relatively well, the mechanism of the unusually strong attachment of the HPI layer to the rest of 


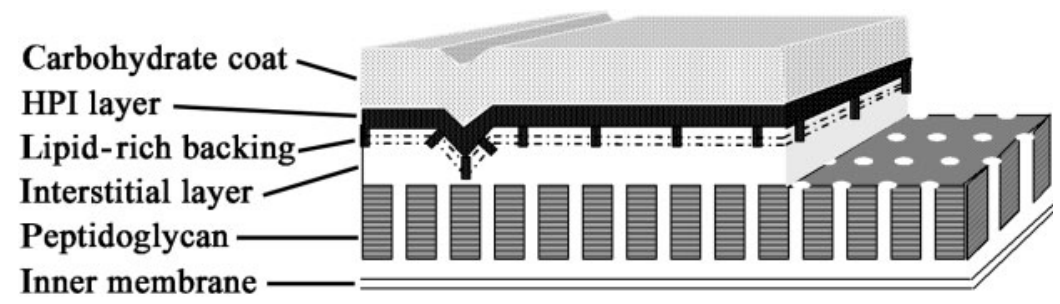

Fig. 1. Proposed structure of the $D$. radiodurans envelope, adapted from Emde et al. (1980).

the pink envelope has not yet been determined. Therefore, we performed phenotypic tests and conducted electron microscopy to determine the role of HPI and another potential S-layer protein, SlpA, in the maintenance of cell envelope integrity in $D$. radiodurans.

\section{METHODS}

Bacterial strains and growth conditions. Escherichia coli JM 109 (Stratagene) was grown in Luria-Bertani broth or on agar plates at $37^{\circ} \mathrm{C}$ in the presence of $50 \mu \mathrm{g} \mathrm{ml}^{-1}$ ampicillin or kanamycin. $D$. radiodurans $\mathrm{R} 1$ (ATCC 13939) strains were grown in tryptone/glucose/yeast extract (TGY; Murray, 1992) at $30{ }^{\circ} \mathrm{C}$ on agar plates or in broth with shaking at 250 r.p.m. The following antibiotics were used: chloramphenicol, $3 \mu \mathrm{g} \mathrm{ml}^{-1}$; kanamycin, $8 \mu \mathrm{g} \mathrm{ml}^{-1}$ in agar plates and $4 \mu \mathrm{g} \mathrm{ml}^{-1}$ in liquid cultures.

Chromosomal DNA preparation. A protocol for chromosomal DNA mini-preparation from $D$. radiodurans was developed, based on the larger-scale method published earlier (Udupa et al., 1994), as follows. Cells were harvested from $1 \mathrm{ml}$ culture in late-exponential to stationary-phase growth by centrifugation for $2 \mathrm{~min}$ at $16000 \mathrm{~g}$ in a tabletop centrifuge. Cells were resuspended in $500 \mu \mathrm{l}$ lysis buffer, consisting of $50 \mathrm{mM}$ Tris/ $\mathrm{HCl}, \mathrm{pH} 8 \cdot 0,50 \mathrm{mM}$ EDTA, $0 \cdot 2 \mathrm{M} \mathrm{NaCl}, 2 \mathrm{mg}$ lysozyme $\mathrm{ml}^{-1}, 200 \mu \mathrm{g} \mathrm{ml}^{-1}$ each of proteinase $\mathrm{K}$ and Pronase E (Epicentre), and $0.6 \%$ SDS. Cells were incubated in this solution for $4-24 \mathrm{~h}$, until lysis was apparent. Protein was removed by one or two extractions by phenol/chloroform/isoamyl alcohol (Roche), followed by one extraction by $0.5 \mathrm{ml}$ chloroform. The upper layer was added to $1 \cdot 2$ vols 2-propanol and inverted 15 times to precipitate DNA. The DNA was collected by centrifugation or spooled onto a glass rod, washed with ice-cold $70 \%(\mathrm{v} / \mathrm{v})$ ethanol, allowed to dry, and dissolved in 50-200 $\mu \mathrm{l} \mathrm{0.1} \mathrm{M} \mathrm{Tris} \mathrm{buffer,}$ $\mathrm{pH} 8 \cdot 0$.

Electroporation. A new method for generating competent cells was developed and optimized as follows. Cells were grown in $50 \mathrm{ml}$ TGY to early exponential phase $\left(\mathrm{OD}_{600}=0 \cdot 4-0 \cdot 6\right)$, chilled on ice for $30 \mathrm{~min}$, and pelleted by centrifugation at $4{ }^{\circ} \mathrm{C}$ for $8 \mathrm{~min}$ at $2700 \mathrm{~g}$. Cells were then resuspended in $10 \mathrm{ml} 0.1 \mathrm{mM}$ HEPES buffer, $\mathrm{pH} 8 \cdot 0$, pelleted as above, resuspended in the same volume of buffer, pelleted again and resuspended in $5 \mathrm{ml}$ of the buffer. Cells were pelleted once again and resuspended in $10 \mathrm{ml}$ sterile ice-cold $10 \%(\mathrm{v} / \mathrm{v})$ glycerol, pelleted again and finally resuspended in $1 \mathrm{ml}$ $10 \%$ glycerol. Aliquots $(100 \mu \mathrm{l})$ were frozen at $-80{ }^{\circ} \mathrm{C}$ for up to 6 months. The highest transformation efficiencies were obtained when the cells were electroporated at $10 \mathrm{kV} \mathrm{cm}^{-1}$ in a $0.2 \mathrm{~cm}$ electrode gap cuvette (data not shown). This voltage was routinely used with a capacitance of $25 \mu \mathrm{F}$ and resistance of $200 \Omega$. TGY broth $(1 \mathrm{ml})$ was added, following by incubation at $30^{\circ} \mathrm{C}$ with shaking for $1 \mathrm{~h}$ (plasmids) or $12-18 \mathrm{~h}$ (to complete chromosomal insertion), and then plating to selective media.

Colony PCR. A sterile platinum wire was used to transfer cells from a single colony to $20 \mu \mathrm{l} \mathrm{PCR} \mathrm{master-mix} \mathrm{(Invitrogen),} \mathrm{to}$ which $5 \%(\mathrm{v} / \mathrm{v})$ DMSO was added. PCR was carried out according to the manufacturer's instructions (Invitrogen), with an additional $5 \mathrm{~min}$ at $95^{\circ} \mathrm{C}$ before the first cycle, and an annealing temperature of $52^{\circ} \mathrm{C}$. Primers used are listed in Table 1.

RT-PCR. The expression of DR2508 and DR2577 was confirmed by analysing RNA prepared from wild-type $D$. radiodurans $\mathrm{R} 1$ grown at $30^{\circ} \mathrm{C}$ as previously reported (Schmid et al., 2005), and carrying out PCR with the internal primers listed in Table 1. The PCR was carried out with 'Ready To Go' RT-PCR beads (Amersham) according to the manufacturer's guidelines. Product-size controls were also carried out with the chromosomal DNA template.

Generation of deletion mutants $\Delta h p i(D R 2508)$ and $\Delta s / p A$ (DR2577). The allelic exchange vector pCM184 (Marx \& Lidstrom, 2002) was modified for use in D. radiodurans by cutting out the tetracycline-resistance cassette and the IncP origin of transfer, and replacing them with a fragment of pI8 (Meima \& Lidstrom, 2000) containing a promoter originally obtained from D. radiodurans SARK followed by the chloramphenicol-resistance gene, to generate pHMR173. This promoter is not found in the D. radiodurans $\mathrm{R} 1$ chromosome and was chosen to avoid undesirable recombinations within the chromosome. This vector was further modified by the addition of a minimal groESL promoter upstream of the kanamycin cassette but still within the loxP sites. The primers mini-PgroF and mini-PgroR (Table 1) were designed to amplify the $48 \mathrm{bp}$ region of the $D$. radiodurans $\mathrm{R} 1$ groESL promoter containing the transcription start site and the -10 and -35 regions. Each primer was designed to contain a DraIII site (in bold type in Table 1) to facilitate cloning. The 72 bp PCR product was generated with the D. radiodurans R1 chromosomal DNA as template, cut with DraIII, and inserted directionally into the non-palindromic DraIII site upstream of the kanamycin cassette to drive kanamycin resistance in D. radiodurans $\mathrm{R} 1$. The insertion was verified by PCR. The resulting vector, pHMR186, contained multiple cloning sites on either side of the loxP-flanked kanamycin cassette. To generate the deletion mutants, PCR products were generated complementary to the regions upstream and downstream of $h p i$ and $s l p A$. Primers were specifically designed to delete the entire target genes, essentially as described by Marx \& Lidstrom (2002). The PCR products were sequenced to ensure that no errors were introduced during PCR. The resulting allelic exchange vectors pHMR202 (containing hpi) and pHMR195 (containing slpA) were transformed into $D$. radiodurans $\mathrm{R} 1$, and colonies selected in the presence of kanamycin. To identify double-crossover recombinants, colonies were screened for chloramphenicol sensitivity on plates. Complete deletion was further confirmed by negative PCR tests with primers targeted to the $5^{\prime}$ and $3^{\prime}$ regions of each gene. Primer sets used in this study are listed in Table 1 . We also constructed pHMR179 expressing Cre recombinase on the D. radiodurans-E. coli shuttle vector pRAD1 (Meima \& Lidstrom, 2000), appropriate for generating unmarked mutants by excising the kanamycin-resistance cassette (data not shown).

Transmission electron microscopy. Cells were washed with double-distilled water and fixed in modified Karnovsky's fixative (2\% paraformaldehyde, $2.5 \%$ glutaraldehyde, $8 \mathrm{mM} \mathrm{CaCl}_{2}$ in $0 \cdot 1 \mathrm{M}$ cacodylate buffer, $\mathrm{pH} 7 \cdot 4$ ) for $2 \mathrm{~h}$ at $4{ }^{\circ} \mathrm{C}$. Samples were washed in cacodylate buffer and post-fixed in $1 \%$ osmium tetroxide 
Table 1. PCR primers and purposes of products

$\mathrm{Cm}$, chloramphenicol; kan, kanamycin.

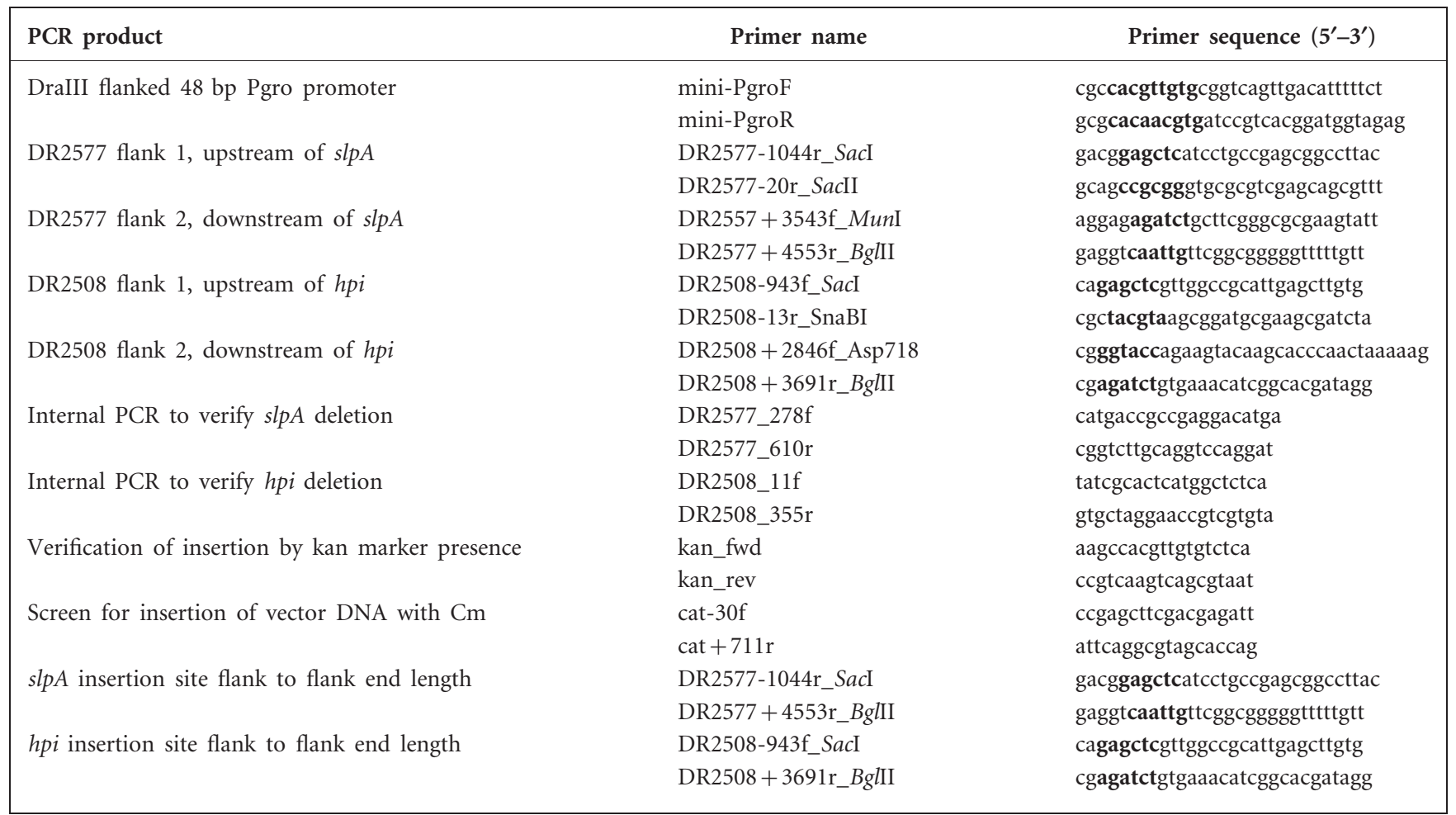

in buffer for $2 \mathrm{~h}$ at room temperature. Following three $5 \mathrm{~min}$ wash steps, cells were embedded in $1.5 \%$ Noble agar and dehydrated in a graded series of ethanol $(35,50,70,80,90,95,100 \%)$. Blocks were then infiltrated at three concentrations of Spurr's reagent using propylene oxide as the transition solvent, and ending in $100 \%$ Spurr's resin. Thin sections of samples were stained with $7 \%$ uranyl acetate and Reynolds lead citrate for 20 and $10 \mathrm{~min}$, respectively. Samples were viewed using a JEOL 1200 Ex II transmission electron microscope operated at $80 \mathrm{kV}$.

Scanning electron microscopy (SEM). Cells were fixed as described above, washed three times for 5 min with double-distilled water, spotted onto plastic cover slips coated with $1 \%$ poly-L-lysine, dehydrated in a graded series of ethanol to $100 \%$, and critical point dried. Samples were sputter coated with gold/palladium, and viewed with a JEOL, JSM 6300F scanning electron microscope at $15 \mathrm{kV}$.

Protein analysis. Overnight cultures of $D$. radiodurans $\mathrm{R} 1$ and HMR195 were left without shaking for 12-16 h to allow natural settling of cells. After settling, the supernatant of the D. radiodurans HMR195 mutant was cloudy and contained visible flocs, whereas that of the wild-type strain was clear. Proteins were extracted from $3 \mathrm{ml}$ of the supernatants using chloroform: methanol $(1: 2)$. The $D$. radiodurans $\mathrm{R} 1$ wild-type pellet was resuspended in $25 \mu \mathrm{l}$ SDS-PAGE loading buffer (Sambrook et al., 1989), and the HMR195 pellet was resuspended in $50 \mu \mathrm{l}$ loading buffer, and both were boiled for $5 \mathrm{~min}$ at $95^{\circ} \mathrm{C}$, after which equal volumes were loaded onto an $8 \%$ polyacrylamide gel along with molecular mass markers (Fermentas). Three of the most prominent bands from the D. radiodurans HMR195 supernatant were cut out of the gel.

Gel slice digestion and protein identification were performed by the Proteomics and Spectroscopy Laboratory at the Fred Hutchinson Cancer Research Center, Seattle, WA, by the following method.
Proteolytic digestion of Coomassie-stained gel slices was carried out as described by Shevchenko et al. (1996). Following digestion, samples were desalted using a microC18 ZipTip (Millipore) and dried. Samples were then resuspended in $7 \mu \mathrm{l} 0 \cdot 1 \%$ trifluoroacetic acid (TFA) and analysed by liquid chromatography electrospray ionization tandem mass spectrometry (LC/ESI MS/MS) with an LCQ DECA XP mass spectrometer (ThermoElectron), using an instrument configuration described by Gatlin et al. (1998). Data were collected in a datadependent mode in which a MS scan was followed by MS/MS scans of the three most abundant ions from the preceding MS scan. MS data were searched against the D. radiodurans protein database (White et al., 1999), using the software search algorithm COMET (Institute for Systems Biology). Protein identifications were considered valid if at least two peptides were matched to a protein and if the peptide matches had raw scores greater than 200 for +1 ions, 300 for +2 ions, and 300 for +3 ions, $\mathrm{Z}$ scores greater than 4 , and percentage ions of greater than $15 \%$.

Shear stress survival assay. Overnight cultures of $D$. radiodurans $\mathrm{R} 1$ and the deletion mutants in hpi (HMR202) and slpA (HMR195) were diluted to $\mathrm{OD}_{600} 0 \cdot 5 \mathrm{in} 1 \mathrm{ml} 1 \mathrm{mM}$ HEPES buffer with $500 \mu \mathrm{l}$ of $0.1 \mathrm{~mm}$ zirconium-silica beads added. Cell suspensions were exposed to shear stress by vortexing for varying lengths of time ( 0 , 30,120 or $240 \mathrm{~s}$ ). Survival was assessed by serial dilutions, spotting $5 \mu \mathrm{l}$ aliquots of each dilution in triplicate onto TGY plates. c.f.u. were calculated from the spot of each dilution series with countable colonies. Because of the aggregation of $\operatorname{slp} A$ mutant cells, the survival rate was underrepresented at $0 \mathrm{~min}$, but after samples were vortexed for $30 \mathrm{~s}$, the colony count increased. To adjust for this factor, all cultures were normalized to the c.f.u. counts after $30 \mathrm{~s}$ of vortexing.

Growth in the presence of toluene. Cells were streaked from frozen stocks onto TGY plates containing antibiotics, as appropriate. A single colony was grown overnight at $30^{\circ} \mathrm{C}$ with shaking in $2 \mathrm{ml}$ 
TGY broth with antibiotics if needed, and $0 \cdot 25-1 \mathrm{ml}$ was transferred to $25 \mathrm{ml}$ TGY without antibiotics in a $250 \mathrm{ml}$ flask. After growth overnight, the OD was measured using a Klett colorimeter (KlettSummerson) that had been calibrated to a spectrophotometer at $600 \mathrm{~nm}$. Cultures were diluted in Klett flasks to the OD corresponding to early exponential phase (a Klett value of $20-25, \mathrm{OD}_{600}$ of about $0 \cdot 16-0 \cdot 2$ ) in $12.5 \mathrm{ml}$ TGY broth, and were capped with rubber stoppers. The initial OD was recorded and deviations in readings due to the vials were subtracted from this and subsequent readings. The cultures were grown with shaking at $30{ }^{\circ} \mathrm{C}$ and checked hourly until reaching a density of $40-45$ Klett units. At this point, the vials were briefly removed from the shaker to add the appropriate amount of toluene, restoppered tightly, and the stoppers were sealed with Parafilm to prevent loosening. The stoppers were not removed after this time, and measurements were taken using the Klett colorimeter until readings stabilized in stationary phase.

\section{RESULTS}

\section{Identification of putative S-layer genes}

The hpigene (DR2508) has been annotated in the genome of D. radiodurans $\mathrm{R} 1$ (White et al., 1999) by its homology with the hpi gene from the D. radiodurans SARK strain (Peters \& Baumeister, 1986). To identify additional candidates for Slayer proteins, we searched the $D$. radiodurans $\mathrm{R} 1$ genomic sequence for genes containing the S-layer homology (SLH) domain (White et al., 1999). Among several other putative S-layer-related protein genes, DR2577, DR1124 and DR0115 were identified as containing domains resembling the annotated SLH domain. The corresponding gene products are predicted to have molecular masses of 124, 43 and $31 \mathrm{kDa}$, respectively. DR2577 revealed homology to an Slayer protein (SlpA) from a related organism, Thermus thermophilus HB8 (25\% identity and $37 \%$ similarity at the amino acid level), suggesting that DR2577 was a candidate for a secondary S-layer protein in $D$. radiodurans $\mathrm{R} 1$. DR2577 was therefore chosen for further experimentation. For the purpose of this study, we henceforth refer to DR2577 as $\operatorname{slp} A$.

\section{Deletion of the hpi and s/pA genes}

We first tested the expression of $h p i$ and $\operatorname{sip} A$ in $D$. radiodurans $\mathrm{R} 1$ via $\mathrm{RT}$-PCR, and obtained positive results (data not shown), indicating that $h p i$ and $s l p A$ are actively expressed in D. radiodurans wild-type. In order to determine the possible roles of $\mathrm{Hpi}$ and SlpA in cell growth, morphology, and resistance to shear and solvent stresses, deletion mutants in both genes were generated, resulting in the mutants HMR202 (defective in hpi) and HMR195 (defective in $\operatorname{sl} p A$ ). We further attempted to generate a double hpilslpA mutant, but these efforts were not successful, possibly due to alterations in the cell envelope that might have either interfered with cell competency or reduced viability during electroporation and $\mathrm{CaCl}_{2}$ treatment (data not shown).

\section{Growth phenotypes of the HMR202 (hpi) and HMR195 (s/pA) mutants}

When grown in TGY broth at $30{ }^{\circ} \mathrm{C}$, the HMR202 (hpi) mutant and wild-type demonstrated equivalent doubling times, whereas that of the HMR195 mutant was about twice the doubling time of the wild-type (Fig. 2), although a similar OD was eventually reached after several days of growth. Mutant HMR195 $(\operatorname{slp} A)$ revealed a tendency toward clumping, with the clumps resembling highly disordered masses of cells under phase-contrast light microscopy (data not shown). Furthermore, we observed that one of the pair of dividing cells in $D$. radiodurans tetrads would often be much smaller than the other. This suggested that normal cellular division was impaired in the slpA mutant strain (data not shown). The colony morphology of mutant HMR195 ( $s l p A)$ also differed from that of the wild-type: the normally smooth and shiny colonies instead appeared rugose and powdery, and were easily broken up with an inoculating loop.

\section{Electron microscopy of $D$. radiodurans R1 and the HMR202 (hpi) and HMR195 (s/pA) mutants}

Thin section microscopy (Figs 3, 4, 5 and 6) and SEM (Fig. 7) were used to visualize the effects of the mutations on $D$. radiodurans whole-cell and envelope morphology. The HMR202 (hpi) mutant did not appear significantly altered in thin section micrographs. The most obvious change was that the peptidoglycan layer seemed to stain more completely and appeared more dense, while the areas surrounding the peptidoglycan layer appeared less dense than in the wild-type cells. It also appeared, in general, that the outer layer containing the backing layer, the HPI layer and the carbohydrate coat was not as thick in this mutant as in the wild-type cells. SEM also revealed few differences

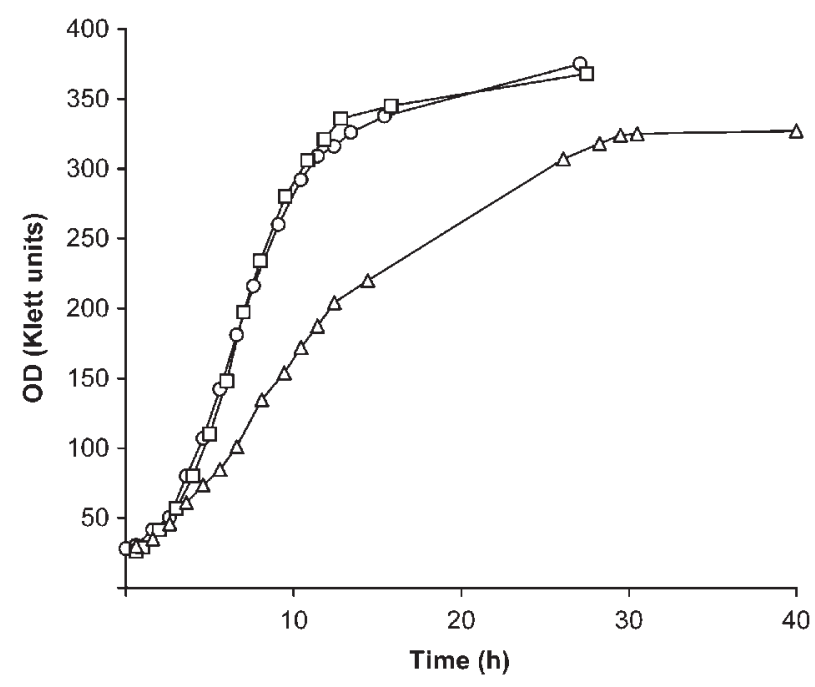

Fig. 2. Growth of $D$. radiodurans $\mathrm{R} 1(\bigcirc)$, and the hpi $(\square)$ and $\operatorname{slpA}(\triangle)$ mutants in TGY broth. 

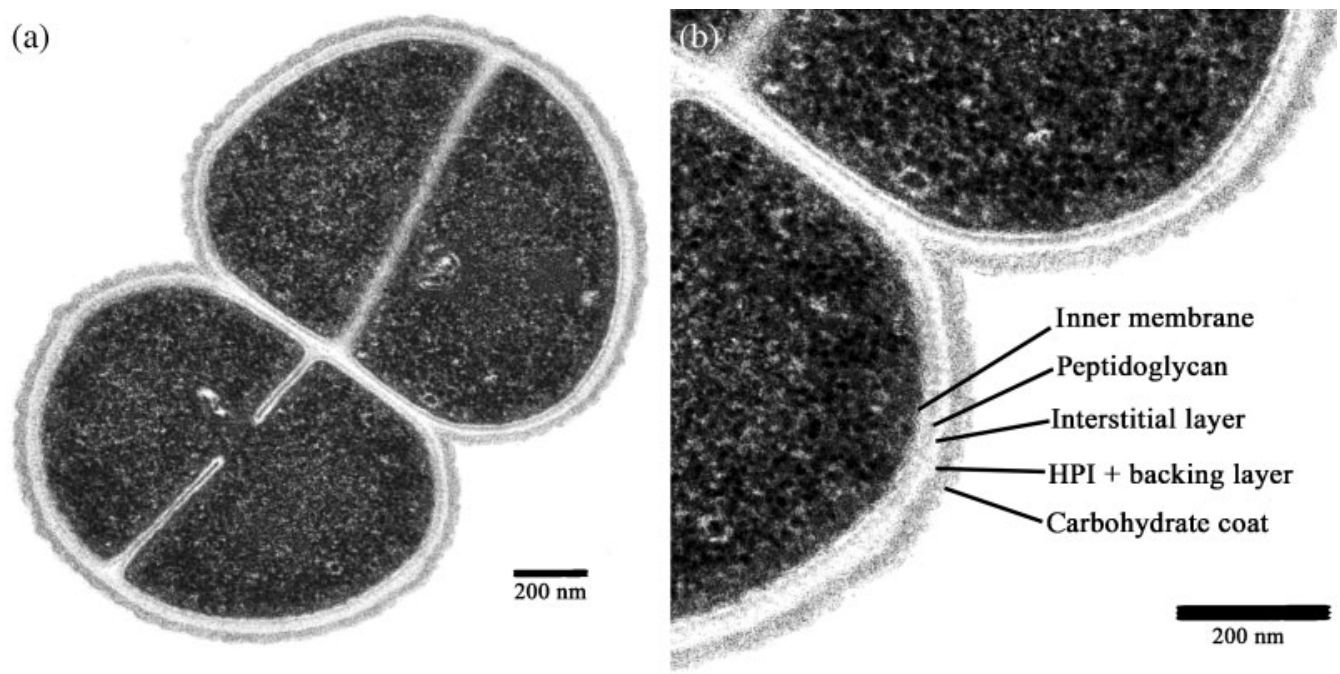

Fig. 3. Thin section electron micrograph of (a) D. radiodurans R1 tetrad and (b) magnification of the membrane. Layers corresponding to those in Fig. 1 are indicated.

between the HMR202 mutant and the wild-type strain. The shape of the cells did not seem affected, and the overall tetrad shape appeared similar. However, the surfaces of the HMR202 mutant cells appeared smoother than in the wildtype. In particular, they lacked the 'mushroom shapes' or 'beads' (Baumeister \& Kübler, 1978; Thornley et al., 1965), which can clearly be seen in the SEM image of wild-type cells (Fig. 7a).

In contrast, the envelope of the HMR195 $(\operatorname{slp} A)$ mutant was clearly compromised. As seen from thin section micrographs (Fig. 5), the outer layers appeared to be detached from the cell and peeling in places. However, we observed that the peptidoglycan layer and perhaps some of the interstitial layer remained attached (Fig. 6b). SEM also showed dramatic differences between the HMR195 mutant and wild-type cells (Fig. 7c). In summary, the electron microscopy images suggested that the mutant cells were shedding exterior layers of the cellular envelope.

\section{Analysis of supernatant proteins in the HMR195 mutant}

If left without shaking overnight, D. radiodurans R1 wildtype cells settle at the bottom of the flask, leaving a visually clear supernatant. This is also true of $D$. radiodurans HMR202 (hpi mutant). However, in D. radiodurans HMR195 (slpA mutant) culture, flocs of material were visible, even after several days without shaking. To examine this material, proteins were extracted from the supernatant,
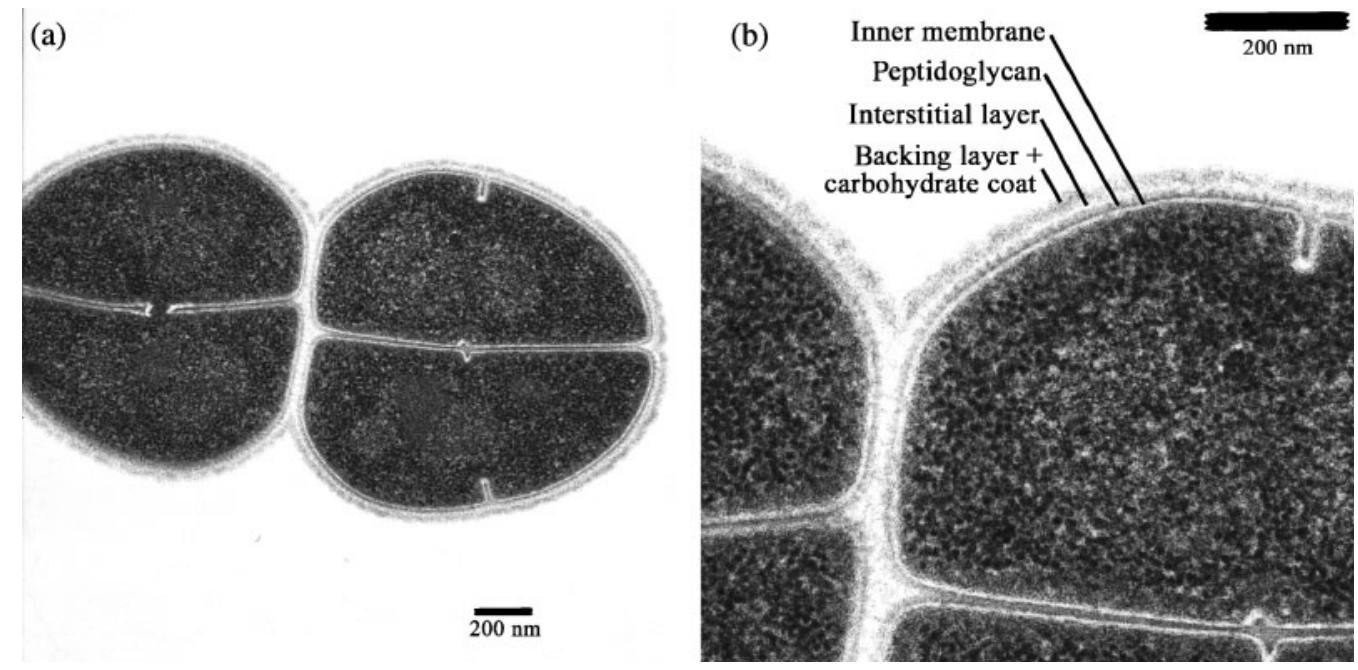

Fig. 4. Thin section electron micrograph of (a) D. radiodurans hpi mutant tetrad and (b) magnification of the membrane. 

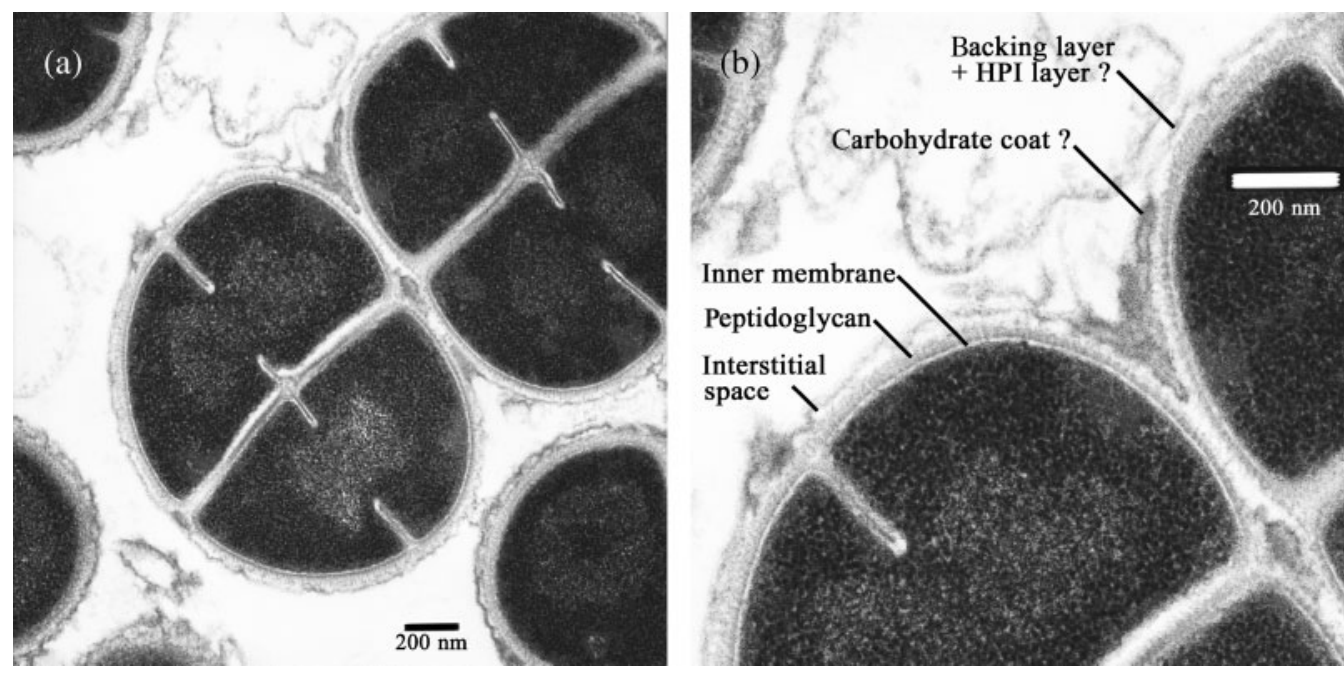

Fig. 5. Thin section electron micrograph of (a) D. radiodurans $s / p A$ mutant tetrad and (b) magnification of the membrane.

concentrated, and analysed by SDS-PAGE along with the $2 \times$ concentrated supernatant from the $D$. radiodurans $\mathrm{R} 1$ culture. Much more protein was extracted from the HMR195 mutant supernatant compared to the wild-type supernatant, as seen on the gels (Fig. 8). In particular, two bands of around $100 \mathrm{kDa}$, and one band of around $35 \mathrm{kDa}$, seemed to be significantly and specifically enriched in the mutant supernatant. The two $100 \mathrm{kDa}$ bands (labelled 1 and 2 in Fig. 8) and the $35 \mathrm{kDa}$ band (labelled 3) were removed from the gel and analysed by MS (Table 2). Bands 1 and 2 were both identified as the Hpi (DR2508) protein. The $35 \mathrm{kDa}$ band was very clearly dominated by the DR 1185 protein, annotated as an S-layer-like, array-related protein in the genomic database (White et al., 1999). Together with the electron microscopy results, this suggests that the flocculent material in the $\operatorname{slp} A$ mutant supernatants consists of shed membrane components.

\section{Stress resistance of the HMR202 and HMR195 mutants}

To understand the involvement of Hpi and SlpA proteins in maintenance of cellular integrity, the resistance of mutant cells to solvents and the ability to survive shear stress were studied. Fig. 9 shows the survival curves at $30 \mathrm{~s}$ to $4 \mathrm{~min}$ of continuous vortexing. Because disassociation of cellular clumps in the HMR195 mutant culture occurred during the first $30 \mathrm{~s}$ of vortexing, survival was normalized to total c.f.u. after 30 s. D. radiodurans $\mathrm{R} 1$ showed no appreciable loss of survival over this first $30 \mathrm{~s}$ time period (data not shown). The survival of the HMR202 ( $h p i$ ) mutant was not significantly lower than that of the wild-type strain after $4 \mathrm{~min}$ of vortexing, whereas in contrast, the survival of the HMR195 $(\operatorname{slp} A)$ mutant dropped one and a half orders of magnitude, suggesting that SlpA contributes to shear stress resistance.

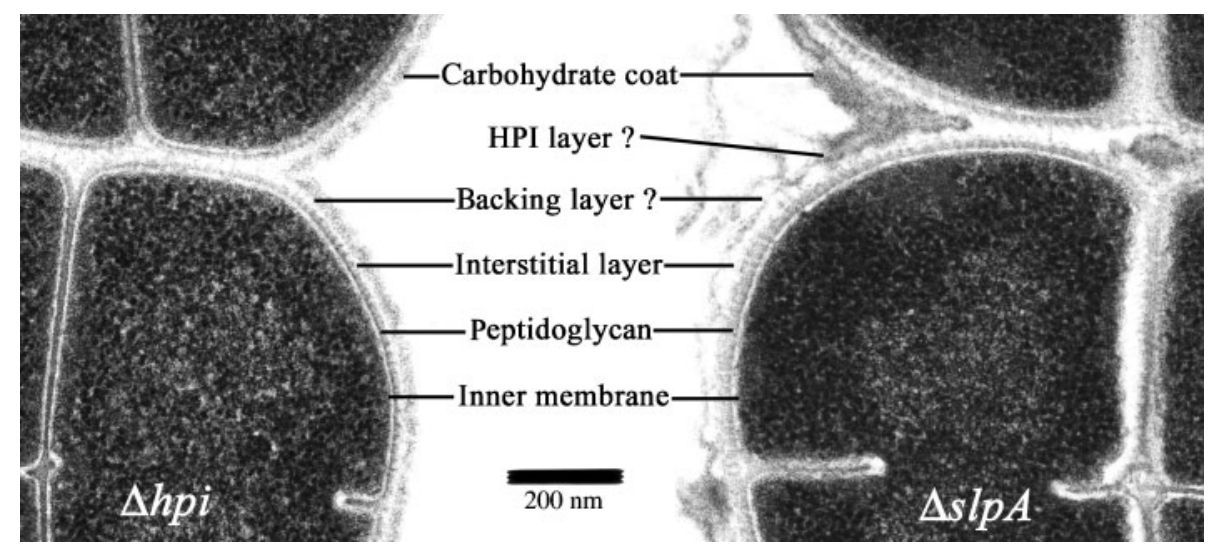

Fig. 6. Magnified thin section micrographs comparing $D$. radiodurans hpi and s/pA mutant envelopes. 

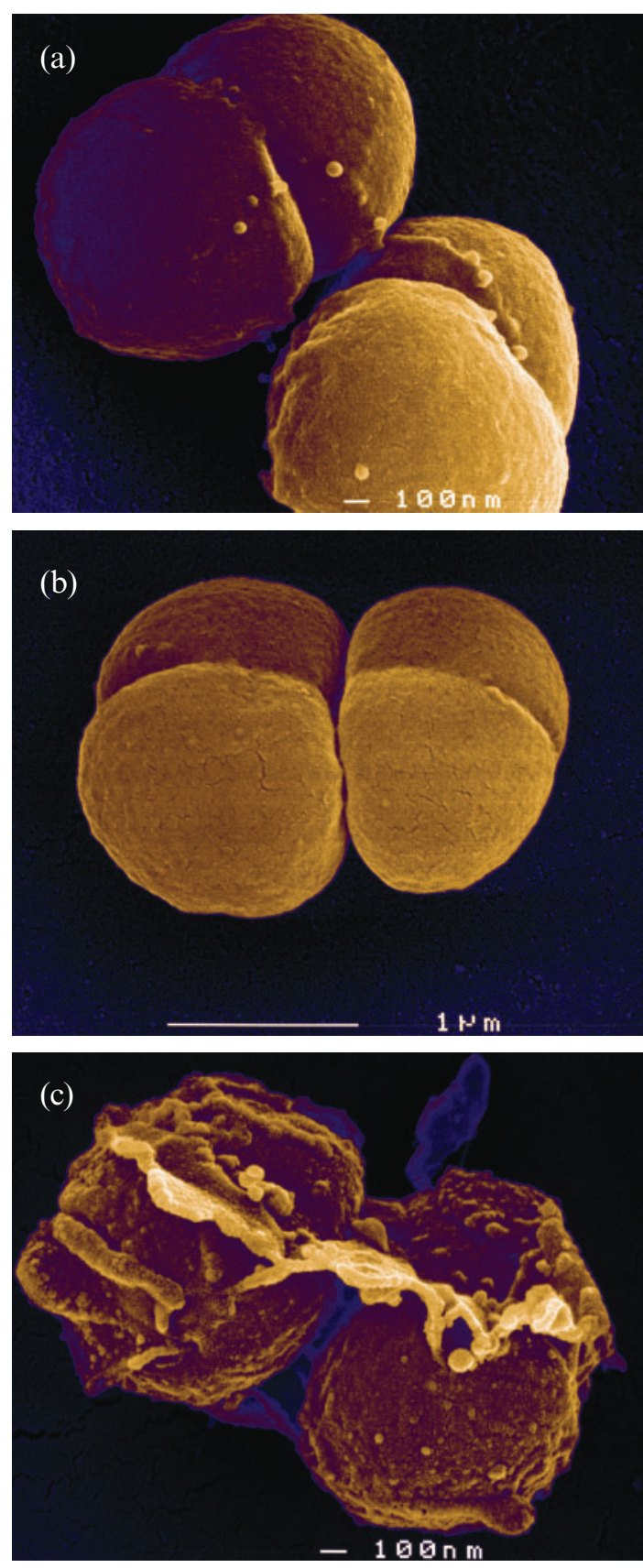

Fig. 7. Scanning electron micrographs of the surfaces of (a) $D$. radiodurans $\mathrm{R} 1$, (b) the hpi mutant and (c) the $s / p A$ mutant. The images have been colourized to display surface features. Bars: (a) $100 \mathrm{~nm}$; (b) $1 \mu \mathrm{m}$; (c) $100 \mathrm{~nm}$.

When grown with $0 \cdot 5 \%$ toluene, the HMR202 (hpi) mutant showed a slower exponential-phase growth rate and a lower cell density in the stationary phase compared to wild-type (Fig. 10). In contrast, the HMR195 (slpA) mutant was again dramatically affected, showing no significant growth over $60 \mathrm{~h}$ after the addition of toluene. Taken together, these results suggest that SlpA may play a significant role in

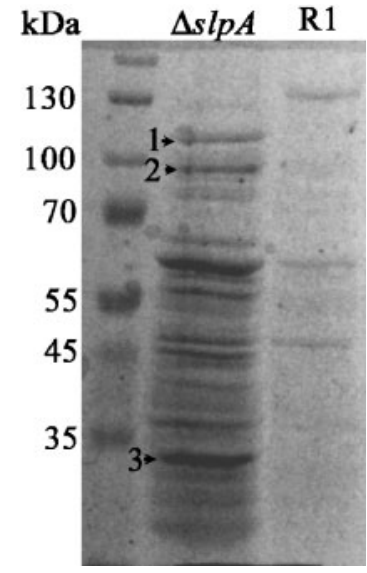

Fig. 8. SDS-PAGE of the supernatants of the $D$. radiodurans s/pA mutant culture and the R1 wild-type culture.

maintenance of cell integrity, whereas Hpi appears to play a minor role.

\section{DISCUSSION}

The structure of the $D$. radiodurans cell envelope has been under study for almost 40 years. The order of the layers of the envelope and the nature of some of these layers have been determined (Baumeister et al., 1986; Emde et al., 1980; Peters et al., 1987), but several questions remain regarding the structure, and little is known about the potential functions of the $S$ layer. In this study, we mutated genes encoding two of the S-layer proteins, $h p i$ and $\operatorname{sp} A$, and studied phenotypes of the resultant mutants. Although spontaneous mutants lacking an HPI layer have been described in D. radiodurans SARK (Thompson et al., 1982), this is the first study conducted with a genetically defined $h p i$ mutant. The phenotype of the HMR202 (hpi) mutant indicates that the HPI layer is required for the formation of external features of $D$. radiodurans $\mathrm{R} 1$. The rippled 'grapeskin' appearance of $D$. radiodurans was first described in 1965 by Thornley and co-workers (Thornley et al., 1965). This topography has also been described as irregular granules' or 'small bead-like structures' on the surface of the cells (Baumeister \& Kübler, 1978). The hpi mutant generated in this study appeared to lack both of these structures, while they appeared to be present in the $\operatorname{slp} A$ mutant. Whether the bead structures fulfil some function or are simply remnants of S-layer irregularities at the points of division remains unclear. However, the HPI layer does seem to be involved in both the outer cell smoothness and the formation of small bead-like structures on the outer surfaces of $D$. radiodurans. Likewise, the functions tested in this mutant, resistance to vortexing (as a measure of shear stress) and resistance to toluene, were only minimally affected, suggesting that Hpi does not play a major role in these outer-layer-related functions. 
Table 2. Identification of proteins enriched in the supernatant of the $\operatorname{s} / p A$ mutant

Band numbers correspond to those shown in Fig. 8.

\begin{tabular}{|lcccc|}
\hline Band & Protein & $\begin{array}{c}\text { Molecular weight } \\
(\mathbf{k D a})\end{array}$ & $\begin{array}{c}\text { Amino acid coverage } \\
(\%)\end{array}$ & Description \\
\hline 1 & DR2508 & $99 \cdot 4$ & $44 \cdot 3$ & Hpi \\
2 & DR2508 & $99 \cdot 4$ & $43 \cdot 4$ & Hpi \\
3 & DR1185 & $36 \cdot 7$ & $79 \cdot 8$ & S-layer-like array-related protein \\
\hline
\end{tabular}

The structural phenotype of the HMR195 ( $\operatorname{sl} A$ ) mutant was much more dramatic. From the microscopy studies, it appeared that layers were peeling from the surface of the mutant cells. Tests for supernatant proteins in the HMR195 mutant revealed that these layers must have contained Hpi and DR1185, a protein annotated as an S-layer-like, arrayrelated protein (White et al., 1999). This phenotype is similar to that of the SIpA mutant of T. thermophilus HB8 (Olabarria et al., 1996). In T. thermophilus HB8, SlpA is an Slayer protein possessing the SLH domain near its $\mathrm{N}$ terminus, which is implicated in having a role in attaching to the peptidoglycan layer (Olabarria et al., 1996). The removal of this SLH domain has been shown to result in shedding S layers (Olabarria et al., 1996). In D. radiodurans, the S-layer protein Hpi does not contain an SLH domain. However, our results suggest that $D$. radiodurans SlpA may provide this anchoring function. As it is not possible to identify the HPI layer in thin sections (Thornley et al., 1965), and due to difficulties in determining the structure of such an extremely perturbed cell envelope, we were not able to directly discern which layers were peeling off. However, it is clear that the layers peeling away from the cell surface do not have the original curvature of the cell wall. It has been previously determined that the backing layer of the pink

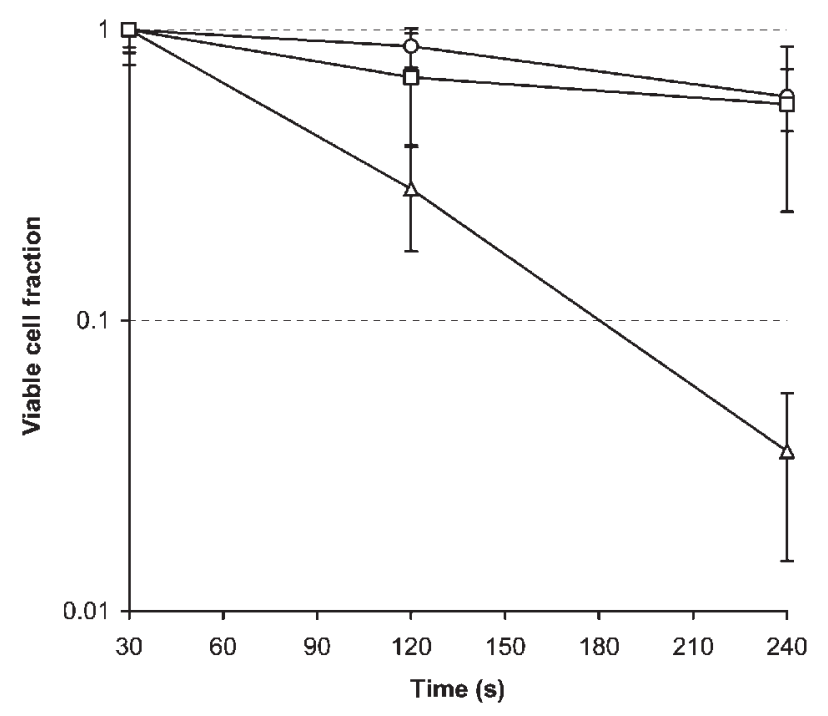

Fig. 9. Survival of $D$. radiodurans $\mathrm{R} 1$ and the S-layer mutants after vortexing. $\bigcirc, \mathrm{R} 1 ; \triangle, \Delta s / p A ; \square, \Delta h p i$.

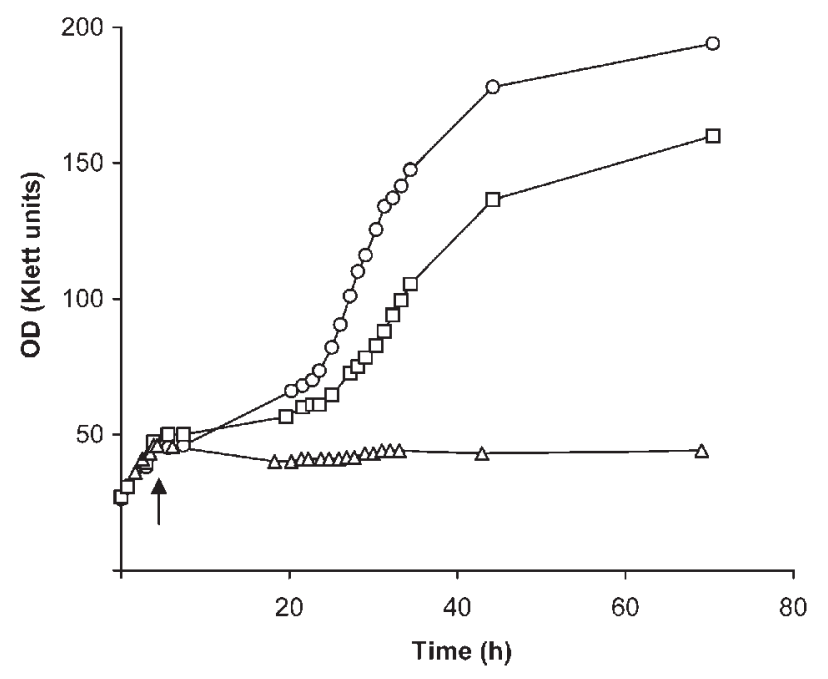

Fig. 10. Growth of $D$. radiodurans $\mathrm{R} 1$ and the $\mathrm{S}$-layer mutants after $0.5 \%$ toluene shock. $\bigcirc, \mathrm{R} 1 ; \triangle, \Delta s / p A ; \square, \Delta h p i$. Arrow, addition of toluene.

envelope, rather than the HPI layer, provides the rigidity and the curvature of the cell envelope (Baumeister et al., 1981), suggesting that the SlpA protein interacts with the backing layer. The $s l p A$ mutant of $D$. radiodurans was also strikingly more sensitive than the wild-type and hpi mutant to both shear and toluene stress, resistance to which is known to be imparted by the cell envelope, thus underscoring the importance of SIpA in outer layer integrity.

\section{ACKNOWLEDGEMENTS}

We are grateful to Kelly Fitzgerald and Christopher Marx for valuable discussion, Mila Chistoserdova and Marina Kalyuzhnaya for helpful comments on the manuscript, and Gloria Jacobson for technical assistance. This work was supported by a grant from the US Department of Energy (ER20294).

\section{REFERENCES}

Baumeister, W. \& Kübler, O. (1978). Topographic study of the cell surface of Micrococcus radiodurans. Proc Natl Acad Sci U S A 75, $5525-5528$. 
Baumeister, W., Kübler, O. \& Zingsheim, H. P. (1981). The structure of the cell envelope of Micrococcus radiodurans as revealed by metal shadowing and decoration. J Ultrastruct Res 75, 60-71.

Baumeister, W., Karrenberg, F., Rachel, R., Engel, A., Ten Heggeler, B. \& Saxton, W. O. (1982). The major cell envelope protein of Micrococcus radiodurans (R1). Structural and chemical characterization. Eur J Biochem 125, 535-544.

Baumeister, W., Barth, M., Hegerl, R., Guckenberger, R., Hahn, M. \& Saxton, W. O. (1986). Three-dimensional structure of the regular surface layer (HPI layer) of Deinococcus radiodurans. J Mol Biol 187, 241-250.

Beveridge, T. J., Pouwels, P. H., Sára, M. \& 22 other authors (1997). Functions of S-layers. FEMS Microbiol Rev 20, 99-149.

Couture-Tosi, E., Delacroix, H., Mignot, T., Mesnage, S., Chami, M., Fouet, A. \& Mosser, G. (2002). Structural analysis and evidence for dynamic emergence of Bacillus anthracis S-layer networks. J Bacteriol 184, 6448-6456.

Emde, B., Wehrli, E. \& Baumeister, W. (1980). The topography of the cell wall of Micrococcus radiodurans. Electron Microsc 2, 460-461.

Gatlin, C. L., Kleemann, G. R., Hays, L. G., Link, A. J. \& Yates, J. R., 3rd (1998). Protein identification at the low femtomole level from silver-stained gels using a new fritless electrospray interface for liquid chromatography-microspray and nanospray mass spectrometry. Anal Biochem 263, 93-101.

Gentner, N. E. \& Mitchel, R. E. (1975). Ionizing radiation-induced release of a cell surface nuclease from Micrococcus radiodurans. Radiat Res 61, 204-215.

Kübler, O. \& Baumeister, W. (1978). The structure of a periodic cell wall component (HPI-layer of Micrococcus radiodurans). Cytobiologie 17, 1-9.

Kuen, B. \& Lubitz, W. (1996). Analysis of S-layer proteins and genes. Chapter 4 in Crystalline Bacterial Cell Surface Proteins, pp. 77-102. Edited by P. M. U. B. Sleytr, D. Pum \& M. Sára. Austin, TX: R. G. Landes.

Kuen, B., Sára, M. \& Lubitz, W. (1996). Heterologous expression and self-assembly of the S-layer protein SbsA of Bacillus stearothermophilus in Escherichia coli. Mol Microbiol 19, 495-503.

Marx, C. J. \& Lidstrom, M. E. (2002). Broad-host-range cre-lox system for antibiotic marker recycling in Gram-negative bacteria. Biotechniques 33, 1062-1067.

Meima, R. \& Lidstrom, M. E. (2000). Characterization of the minimal replicon of a cryptic Deinococcus radiodurans SARK plasmid and development of versatile Escherichia coli-D. radiodurans shuttle vectors. Appl Environ Microbiol 66, 3856-3867.
Murray, R. G. E. (1992). The deinococci. In The Prokaryotes: a Handbook on the Biology of Bacteria: Ecophysiology, Isolation, Identification, Applications. Edited by H. G. T. A. Ballows, M. Dworkin W. Hader \& K. Schleifer. New York: Springer.

Olabarria, G., Carrascosa, J. L., de Pedro, M. A. \& Berenguer, J. (1996). A conserved motif in S-layer proteins is involved in peptidoglycan binding in Thermus thermophilus. J Bacteriol 178, 4765-4772.

Peters, J. \& Baumeister, W. (1986). Molecular cloning, expression, and characterization of the gene for the surface (HPI)-layer protein of Deinococcus radiodurans in Escherichia coli. J Bacteriol 167, 1048-1054.

Peters, J., Peters, M., Lottspeich, F., Schäfer, W. \& Baumeister, W. (1987). Nucleotide sequence analysis of the gene encoding the Deinococcus radiodurans surface protein, derived amino acid sequence, and complementary protein chemical studies. J Bacteriol 169, 5216-5223.

Rachel, R., Pum, D., Šmarda, J., Šmajs, D., Komrska, J., Krzyzánek, V., Rieger, G. \& Stetter, K. O. (1997). Fine structure of S-layers. FEMS Microbiol Rev 20, 13-23.

Sambrook, J., Fritsch, E. F. \& Maniatis, T. (1989). Molecular Cloning: a Laboratory Manual, 2nd edn. Cold Spring Harbor, NY: Cold Spring Harbor Laboratory.

Schmid, A. K., Howell, H. A., Battista, J. R., Peterson, S. N. \& Lidstrom, M. E. (2005). Global transcriptional and proteomic analysis of the Sig1 heat shock regulon of Deinococcus radiodurans. J Bacteriol 187, 3339-3351.

Shevchenko, A., Wilm, M., Vorm, O. \& Mann, M. (1996). Mass spectrometric sequencing of proteins silver-stained polyacrylamide gels. Anal Chem 68, 850-858.

Sleytr, U. B., Messner, P., Pum, D. \& Sára, M. (1993). Crystalline bacterial cell surface layers. Mol Microbiol 10, 911-916.

Thompson, B. G., Murray, R. G. E. \& Boyce, J. F. (1982). The association of the surface array and the outer membrane of Deinococcus radiodurans. Can J Microbiol 20, 1081-1088.

Thornley, M. J., Horne, R. W. \& Glauert, A. M. (1965). The fine structure of Micrococcus radiodurans. Arch Mikrobiol 51, 267-289.

Udupa, K. S., O'Cain, P. A., Mattimore, V. \& Battista, J. R. (1994). Novel ionizing radiation-sensitive mutants of Deinococcus radiodurans. J Bacteriol 176, 7439-7446.

White, O., Eisen, J. A., Heidelberg, J. F. \& 29 other authors (1999). Genome sequence of the radioresistant bacterium Deinococcus radiodurans $\mathrm{R} 1$. Science 286, 1571-1577.

Work, E. \& Griffiths, H. (1968). Morphology and chemistry of cell walls of Micrococcus radiodurans. J Bacteriol 95, 641-657. 